\title{
Resource allocation: whose realism?
}

\author{
P A Lewis University of Wales College of Medicine
}

Our recent paper in this journal (1) was followed, in the same issue, by a response by $\operatorname{Lamb}(2)$ and by a further discussion by Whitaker in the preceding paper of this issue. We would wish to emphasise the following points concerning the basis of our analyses.

1. There is an existing problem, faced on a daily basis by doctors, concerned with establishing the priorities between different patients who all have the same medical condition and require the same treatment with approximately the same short term prognosis. This is a real problem which is having to be solved on a daily basis by the majority of practising clinicians in this country. We cannot help but feel that for one who cites '... today's moral philosophers - whose work, as at no other time, has direct, practical applications ...' Whitaker is abrogating the responsibility of the moral philosopher by failing to address this issue, as he suggests, ' $\ldots$ deciding levels of resources may be a first step to take, before examining strategies for their distribution'. From our own work and experience we know that many clinicians would value guidance in making these everyday decisions and welcome others willing to shoulder the responsibilities of withholding worthwhile treatment (see, for example, case referred to in (3)). By comparison some of the more prominent topics in medical ethics such as abortion and active voluntary euthanasia, while no less worthwhile topics for study, actually arise far less often or apply to far fewer doctors.

2. At no time have we suggested that we would not support substantial increased funding in the health service and our own unpublished data from the Cardiff Health Survey show that a substantial proportion (78 per cent) of the respondents favour a redistribution of the existing level of government expenditure towards the health service. We know of no authoritative agreement to the assertion that there is a viable level of expenditure which will allow all health care needs to be fully met. The case for rationing has not been refuted and is gaining wider acceptance, see for example (4).

3. Are we being uncharitable in thinking that many of

\section{Key words}

Resource allocation; valuation of life; professional responsibility. our academically-minded colleagues are uncomfortable with the requirement to ration worthwhile medical treatment? Thus, might they be sheltering behind possibly spurious academic arguments as a defence against having to address the real problem described above? Whitaker claims: 'We need to know how large are the "large numbers of physicians working in isolation" who apparently make decisions about who to treat and who not to, on the basis of limited resources' (1). One wonders why? Will the problem cease to exist if the number of physicians falls below a particular level? A more precise estimate of the magnitude of the large numbers involved seems a rather low priority when the fundamental problem remains unresolved.

Lamb asserts: 'The problem of bringing true democracy to the health service is inseparable from bringing true democracy to society in general'. Then as a result of his analyses states: 'No matter how accurate public opinion sampling may be, it is neither a more democratic nor a more efficient way of spreading responsibility than a system of random choice'. We take issue with three elements of this. Firstly we only sampled because we were testing the methodology and did not feel that a larger sample was necessary. In practice there is no reason why the members of, say, the electoral register should not be able to express opinions. Secondly, we have no objection in principle to 'random choice' provided it can be demonstrated that this is the preferred option of society. We would point out that it is likely to be 'inefficient' and lead to decisions which seem to be unfair at the individual level, but in so doing we would only wish to influence those proposing or supporting 'random choice', not to withdraw the option altogether. Finally we note that in this country we decide many, but not all, issues by a voting system. If the choices which have to be made cannot be taken by a democratic vote (even with all its well documented imperfections) then who is going to decide? We wish to spread the responsibility of choosing in a democratic way. Nuances concerning whether the solution which we have suggested is more democratic or more efficient in spreading responsibility seem to be secondary factors. Lamb is careful not to state that the method we propose is undemocratic or inefficient in spreading responsi- 
bility. Equally we did not claim that our method was in any sense optimal, just that it would be preferable to what happens now.

4. Whitaker and Lamb have both misunderstood the assumed context of the decision-making process we described. We are dealing with an insurance-based system for the provision of health care. In asking the respondents to the survey to 'choose' we felt that we were trying to access the individuals' different levels of priorities for the allocation of benefits. The structure of the conceptual model was felt to be the same as when deciding which particular benefits would be of value when selecting say motor insurance against a fixed budget. If one knows with certainty that one's windscreen is never going to be shattered then one might not deem that benefit worthwhile. Equally if one had just had one's windscreen shattered the desirability of that benefit would be dramatically changed. We were asking respondents, with little if any knowledge of the future, to select population benefits which would accrue from the population health insurance: that is, what relative responsibilities they feel they have for different future population groups. Note that some of these parameters are unvarying, for example sex, and some may vary, for example age. Whitaker and Lamb both confuse the notion of population responsibility with the special responsibilities that individuals feel for their families and close friends. We were asking what collective relative responsibilities society should have for, say, the young and the elderly. There is no reason why we should want or expect society to have the same responsibility as ourselves for the young and the elderly amongst our own family and friends and vice versa.

We try to decide what benefits should accrue from our insurance-based health service and ensure that these benefits are delivered. If we are unhappy with the general levels of benefits then we are free to change the level of premiums. Alternatively, if we find that the benefits accruing specifically to our families or friends are not sufficient for us as individuals to feel that we have suitably discharged our responsibilities to them then we may be able to divert our personal resources to help discharge this responsibility. Note that we would have an expected level of benefit for each member of society, a circumstance which is sadly lacking at the moment as the level of benefit can usually only be found during the clinical consultation. In the UK we live in a society where different members have different abilities to supplement the service provided by the National Health Service (NHS). We choose not to express a personal view on the desirability or otherwise of this. But under these circumstances it seems to be particularly important that the benefits of the NHS be detailed so that individuals may express views on the appropriateness of the level of benefits or their personal wish to supplement them based on a guaranteed level of benefit. At the moment all debate is hampered by there being no clear descriptions of what are to be the expected benefits or even what the existing benefits are.

The utilitarian principle which underpins our notion of population responsibility is merely a method of obtaining a consensus. In our everyday lives we all probably subscribe to some personal hybrid philosophy, some of whose components were alluded to by Whitaker. Individuals and groups within society find the motivation to complement or supplement what they see as the existing (unwritten) prejudices of the consensus. One only has to study the contribution made by say the Cystic Fibrosis Trust in supplementing the insurance-based benefits accruing to people carrying this genetic disorder to realise that the consensus basis for providing population benefits does not prevent groups from holding and acting on rather different priorities.

5. The last point that Whitaker makes, namely that the legitimisation of discrimination will cause politicians to lose their jobs has not been lost on the politicians. We believe that several of the thrusts of the recent White Paper on the NHS (5) are included specifically because politicians wish to shed themselves of this responsibility. The clinical budget holders, in managing their budgets, (or more specifically balancing their budgets) will not be able to afford to treat everyone but it will now be clearer that they are the architects of the rationing. Once you hold a clinical budget you are accepting the responsibility and blame for withholding worthwhile treatment. We foresee that the debate mats be shifted from the socio-political setting to a sociomedical setting. We believe that clinicians have no more or less rights than the rest of society in establishing these priorities. We would have clinicians as the executors of this aspect of social policy, not its architects.

\section{Acknowledgement}

This manuscript met the very short deadline set by the Editor mainly due to the prompt secretarial service of Mrs Julie Spiteri.

Peter Lewis BTech PhD MBCS is Lecturer in Medical Computing in the Department of Medical Computing and Statistics, University of Wales College of Medicine, Cardiff.

\section{References}

(1) Lewis PA, Charny M. Which of two individuals do you treat when only their ages are different and you can't treat both? Fournal of medical ethics 1989; 15: 28-32.

(2) Lamb D. Priorities in health care: reply to Lewis and Charny. Fournal of medical ethics 1989; 15: 33-34.

(3) Charny M, Lewis PA. Choosing who shall not be treated in the NHS. Social science in medicine 1989; 28: 13311338.

(4) Stanley JM et al. The Appleton Consensus: suggested international guidelines for decisions to forego medical treatment. Fournal of medical ethics 1989; 15: 129-136.

(5) White Paper. Working for patients. London: HMSO, 마 1989. 